\title{
Emotional Dysregulation: The Clinical Intervention of Psychodynamic University Counselling
}

\author{
Francesca Menozzi - Nico Gizzi - Mariateresa Tucci \\ Nazarena Patrizi - Mauro Mosca*
}

Sapienza Università di Roma - Faculty of Medicine and Psychology (Italy)

doi: 10.7358/ecps-2016-014-meno

framenozzi@hotmail.com

nico.gizzi@uniroma1.it

tucci.mariateresa@gmail.com

nazarena.patrizi@uniroma1.it

mauromoscamm@libero.it

\section{DISREGOLAZIONE EMOTIVA: L'INTERVENTO CLINICO FORNITO DAL COUNSELLING PSICODINAMICO UNIVERSITARIO}

\section{Abstract}

The present work aims to discuss the psychodynamic treatment provided in a Counselling Centre for University Students. We present the methodology and procedure of Counselling University Services psychodynamically oriented: the treatment consists of four weekly sessions and a fifth session three months later (follow-up). We will focus on a very frequent clinical topic reported by university students: emotional dysregulation. We will provide two clinical vignettes and report the main effects obtained by psychodynamic counselling on developing adaptive psychological functioning related to an increase in socialization and behavioural autonomy, as well as a greater definition of identity. Finally, in the light of the reflections illustrated, we underline the importance of promoting university counselling services to help students find more functional strategies in their emotion regulation process:

* This article is the result of joint work of the five authors. In detail the $₫ 1$ was written by Francesca Menozzi, the $₫ 2$ by Mauro Mosca, the $₫ 3.1$ by Nico Gizzi, the $₫ 3.2$ by Maria Teresa Tucci and the $\$ 4$ by Nazarena Patrizi. 
from the capacity to read one's emotional states and to give them meaning, to the development of the more adaptive behavioural responses to cope with the developmental tasks and the inevitably linked academic performance.

Keywords: Adaptive functioning, Clinical vignettes, Emotional dysregulation, University counselling, University students.

\section{INTRODUCTION: THE PROBLEM OF EMOTION REGULATION IN THE UNIVERSITY STUDENT}

The student's time at university is a period of growth and development, but also of important changes which can sometimes lead to a deep crisis in the student. In particular, changes due to such things as developing new forms of autonomy, interacting with new social networks, being away from one's family and identifying new strategies in one's study organization can be magnified by developmental conflicts linked to the transition to adulthood and can lead to stress that the student may find difficult to cope with.

The present study aims to deal with some of the most frequent problems reported by students who turned to psychological counselling service for help, in order to highlight how the emotion regulation process is a crucial factor for adjusting to the university context and how the development of these abilities is a safeguarding factor against psychopathological risk (Park, Edmondson, \& Lee, 2012).

Moreover, we aim to illustrate how the difficulties in this emotion regulation process in stress conditions (Biasi, Bonaiuto, \& Giannini, 2010) can determine different responses in student functioning and in symptomatology.

Emotional regulation refers to those internal and external processes responsible for monitoring, evaluating and modifying emotional reactions, especially with regard to their intensity and trend over time in order to achieve individual objectives (Thompson, 1994).

Effective emotional regulation is crucial for social functioning and psychological wellbeing, and involves various spheres of functioning such as neurophysiological responses, attentional processes, the coding of internal emotional signals, the ability to adopt coping strategies and alternative adjustment responses (Eisenberg, Fabes, Guthrie, \& Reiser, 2000).

Gratz and Roemer (2004) proposed a multidimensional model of emotional dysregulation highlighting how it reflects: (a) a difficulty in the awareness and comprehension of emotions; (b) a difficulty in accepting emo-

\footnotetext{
ECPS Journal - 14/2016

http://www.ledonline.it/ECPS-Journal/
} 
tions; (c) a difficulty in enacting goal-directed behaviours and in restricting impulsive behaviours when experiencing negative emotions; (d) a difficulty in accessing effective emotional regulation strategies.

In particular, emotional regulation involves processes which enable the evaluation and interpretation of information concerning the emotional sphere, the modulation of the expression of emotions, the handling of emotional experiences, the responses to emotions and the relative thoughts and behaviours (Cole, Martin, \& Dennis, 2004; McLaughlin, Hatzenbuehler, Mennin, \& Nolen-Hoeksema, 2011). An effective emotional regulation is correlated with the use of adaptive coping strategies such as problem-solving and the search for social support, while the behaviours reflecting an avoidance strategy, such as distraction and denial, predict negative outcomes at the emotional and behavioural level (Hayes \& Feldman, 2004; Kassel, Bornovalova, \& Mehta, 2007).

Many studies in the scientific literature show that a disorder in emotional regulation is significant in a broad range of psychopathological disorders (Aldao, Nolen-Hoeksema, \& Schweizer, 2010; Berking \& Wupperman, 2012). In particular, the high level of emotionality due to the many changes, both neurophysiological and socio-environmental, characterising the adolescent and young adult may not be counterbalanced by adaptive coping strategies and can thus become a risk factor for developing emotional and behavioural problems (Spear, 2000, 2013; Steinberg, 2005; Biasi, Mallia, Menozzi, \& Patrizi, 2015).

In a sample of adolescents, McLaughlin, Hatzenbuehler, Mennin and Nolen-Hoeksema (2011) showed how emotional dysregulation is predictive of psychopathological problems and is not a consequence of them. In particular, the authors showed how a deficit in emotional regulation predicts a worsening of anxiety symptoms, aggressive behaviour and eating disorders.

The connection between emotional dysregulation and anxiety was also reported by Mennin, Heimberg, Turk and Fresco (2005), who analyzed a sample of students with generalized anxiety disorder and found a high level of intensity in emotions, poor capacity to recognize emotions, negative reactions to emotional experiences, and a poor ability to console oneself after experiencing negative emotions, thereby reflecting a difficulty in emotional regulation processes. Moreover, some studies on risk behaviours in university student samples highlighted a correlation between emotional dysregulation, suicidal tendencies and self-harm (Rajappa, Gallagher, \& Miranda, 2012; Wilcox, Arria, Caldeira, Vincent, Pinchevsky, \& O’Grady, 2012).

Selby, Anestis and Joiner (2008) examined the relation between emotional dysregulation and the behavioural one, elaborating an «emotional cascade» concept, a process in which individuals implement disadaptive behav- 
iours (such as binge-eating and self-harm) to regulate the stress deriving from the accumulation of negative emotions when it reaches the apex of endurance after cumulative exposure to experiences involving negative emotions.

One difficulty in emotional regulation can also interfere with other aspects crucial for university performance such as the development of a perfectionism which becomes disadaptive since it is focused on constant self-criticism of one's performance (Aldea \& Rice, 2006; Rice \& Van Arsdale, 2010).

Another aspect of fundamental importance for adjustment to the university context concerns the relation with one's peers that many studies have shown to be a protective factor with regard to psychological distress.

In this regard, Lopes, Salovey, Côté, Beers and Petty (2005) showed how an effective emotional regulation is connected to a high quality of social relations in a sample of university students, promoting their interpersonal sensibility and prosocial tendencies.

Finally, in a literature review, Morris, Silk, Steinberg, Myers and Robinson (2007) stressed how the emotional regulation process develops starting from primary relationships with figures of attachment and how the affective atmosphere of the family has an important influence on the development of the capacity to regulate emotions until adolescence, when the social system of peers gradually starts to have greater room with respect to the family one.

In conclusion, these elements highlight how the emotion regulation process involves various aspects which can co-determine the student's adaptive (or disadaptive) functioning and which range from the construction of one's personal identity to the redefinition of interpersonal relations with peers and members of the family.

The two clinical vignettes presented in the following sections will illustrate how all these aspects are inextricably connected and how difficulty in emotion regulation can have a negative impact on the student's academic functioning. The psychological counselling treatment may be a valid instrument to support and help these students to get in better touch with their internal world and to develop more adaptive regulation strategies.

\section{The Psychodynamic Counselling Services FOR UNIVERSITY STUDENTS}

The Psychological Counselling Service for University Students was generally oriented to coping with students' distress and pathological symptoms to be treated in mental health services rather than developmental problems (Hohenshil, Amundson, \& Niles, 2013). 
We now address our attention toward the Counselling for University Students oriented to psychodynamic theoretical framework (see Rizq, 2010), that we consider particularly functional to solve problems concerning students' education and training, and to promote student maturation (Adamo, Sarno, Preti, Fontana, \& Prunas, 2010; Biasi \& Bonaiuto, 2012; Biasi, Bonaiuto, Patrizi, \& Levin, 2015; Monti, Tonetti, \& Ricci Bitti, 2015; Biasi, Patrizi, Mosca, \& De Vincenzo, 2016).

We refers about a specific procedure adopted in different Counselling University Services, that is addressed to students enrolled in different faculties and consists of a cycle of four sessions with a final follow-up session three months later. An expert psychotherapist helps the student to identify and cope with the personal difficulties encountered in his/her university studies and life, creating a personal listening and clarification space in which to establish suitable strategies to cope with students' personal discomfort and difficulties in their university experience. A space in which psychological suffering, initially experienced in a confused and unexpressed manner, can be accepted so that it does not take on pathological connotations or, when they are already present, to facilitate the emergence of a more conscious request for help.

The clinical experience in the counselling of university students highlighted how the difficulty in regulating the emotions is a risk factor for those students who cannot autonomously manage to adapt to their new academic context.

\section{SOME CLINICAL VIGNETTES}

We shall now present two clinical cases exemplifying the major problems reported by the students at a Psychodynamic University Counselling Centre.

\subsection{The Ivana case ${ }^{1}$}

Ivana is a twenty-two year old student who turned to the University Counselling Centre because she was suffering from anxiety, feelings of shame and a sense of emptiness with regard to her future. She felt misunderstood and not welcomed by her family and the social world around her, but also acknowl-

1 According to Italian legislation on privacy (Law 196/2003), students who turn to the Counselling Centre complete and sign an informed consent allowing data entry and storage. In order to ensure student confidentiality, the names have been changed. 
edged that she was not very willing to interact with others. Ivana was in her first year of her master's degree in the performing arts but had not yet sat a single exam because, as she said, her mind was taken up "with other things». The emotion she expressed appeared exaggerated and theatrical: her heightened moods fluctuated and were expressed through crying alternating with sudden laughter, and were at odds with the painful things she was reporting. She said, "I know I can cry here, but I don't want to", thereby taking on a formal attitude and behaviour which showed the activation of defence mechanisms to control her poorly regulated emotions. The emotional discomfort she was experiencing led her to relate to the therapist by focusing on current issues which appeared less involving in order to protect herself by repressing her past painful and distressing experiences. She said that what had made her even more fragile was the loss of some friendships owing to some of her friends going away and this had given her a deep sense of loneliness. She added that this uneasiness also stemmed from a difficult relationship with her father, who she described as an inflexible, stern man that had been a source of suffering for her owing to his various physical mistreatments of her right from her first year at university. When she recalled one episode of physical mistreatment, Ivana initially attributed it to when she was a little child or, in any case, a long time before, but when she was specifically asked how old she was at the time, she said eighteen. In her past recollections and current representation, her father was seen as a powerful man who denigrated her, like he also did with her mother and seventeen-year-old brother who, being a boy, however, managed not to suffer the father's dictatorial and authoritarian behaviour. In Ivana's view, her mother was just as much a victim of her father as she was: her mother was weak and seemed not to have been sufficiently protective towards her in order to make her feel safe from her father's vexations.

Her account was marked by considerable changes in mood which did not seem linked in any coherent way to what she was actually saying. From her accounts of her family history there emerged her tendency to give her family members different power and value according to their gender: she and her mother were weak, while her father and brother were strong. In her account, her father preferred her brother and tended to denigrate her: in her words, «He makes me feel inept, he asks me things and then does as he wants». He described her relationship with him as negative even if she said he kept in constant touch with her, and this confirmed that while, on the one hand, she felt deeply rejected, on the other, she knew she had some form of attraction for him, thereby showing the typical functioning mechanism of a hysterical personality.

While recounting these complex problems recalling negative emotions, Ivana smiled or normalized her mental state: she would comment, «I'm smil- 
ing now, but ...». When faced with her most painful memories in her relationship with her father and in her concerns for wishing to also save her mother from her father's violent manner, her smile turned into tears. During her recollections she expressed herself with some difficulty and the main theme during her crying moments was her conflict with her father and the presence of a mother who was a "friend" that, however, had less substance as the conversation progressed because of not being able to be protective enough.

The contrasting feelings with regard to her parents represented an internal sphere of conflict which Ivana seemed unable to solve. Her capacity to reflect was weak and when she did try to do so or to make connections between her childhood and her experiences, states of anxiety and anger emerged which would bring her to tears that she perceived as unmotivated: «See, I'm crying, but I don't know why ...».

Even in sentimental relationships she perceived that others had little esteem for her. When she recalled the first time she had sexual intercourse, she said it had not been very gratifying and did not remember much about it. She spoke of the event without any emotional involvement and without any details: "Everything happened very quickly ...». Her treatment of other emotionally connected matters was equally brisk. Alongside her feelings of shame and of low self-esteem we found a seductive manner, but helpless and weak.

In her third session Ivana started to talk of her job opportunities, of offers she had received for trials which were unsuccessful, and she said this started to «burden her».

She very conspicuously alternated moments of heightened idealization with belittling thoughts, both with regard to show-business people and some university lecturers. When asked to reflect on the meaning of her choice of studies, she replied that she did not like «always having to stick to a particular role or direction", and that she wanted to be more authentic. Through this metaphor, Ivana described herself as, in actual fact, a girl who had moved with an external direction, without acknowledging her own personal needs and with poor self-determination, probably due to a lack of reflection on the part of her two parent figures who, through a tuning process, should have accompanied her in adjusting her emotional states and to metabolize those that were difficult for a child to understand. Ivana seemed to agree with what she said her father thought about her university studies, as being «abstract and not very useful», and said she would have to make more accurate decisions in the future.

In conclusion, being able to face her emotional dysregulation within a more neutral relational setting as the clinical one enabled Ivana to access other representations both with regard to her choice of university studies very likely chosen for her need to oppose her father (counter-identification) 
and not stemming from a reflection on her own needs and plans for personal self-actualization - and with regard to her approach in interpersonal relations and the strategies she used in order to regulate her emotional gaps with others.

\subsection{The Giulia case ${ }^{2}$}

Giulia was a 24-year-old student who had finished her degree course examinations and was about to do her final examination for her Master's degree. She arranged an appointment and turned up at the Counselling Service Centre for anxiety disorders. Giulia lived with her family of origin, composed of her parents, an older brother and a younger sister.

In her first meeting at the Centre she reported a specific symptom: she had had difficulty in swallowing for about a month and was forced to eat liquid or processed (baby) foods. This led her to social isolation with the avoidance of all those relational situations involving eating: apart from her boyfriend, she did not see many other friends. Her request was to find a solution to her difficulties in swallowing: "What can I do?».

Right from the outset of her treatment it seemed she had difficulty in recognizing her own emotional states, to define them and to attribute meaning to her past experiences. She did not seem aware of the links between the mental representation of affection and her somatic symptom.

During the first meeting, the counsellor tried to create a climate of trust in which Giulia could feel welcome and understood. In analyzing the symptom it turned out that she had already experienced it when she was 17, during her first holiday alone with her boyfriend. On that occasion she did not do anything about it and the symptom soon went away. When the hypothesis was put to her that her symptom appeared when she felt she was about to enter the adult world, she replied: «I had never thought of that before, but this is actually the case». Giulia would typically respond to any interpretation, acknowledging it with amazement, for "not having thought about it before».

She appeared involved in emotions that had not been sufficiently processed, thought about, "digested», that is, thoughts which she found "difficult to swallow for fear of choking» and which led her to eat like babies in their weaning phase. She also reported being anxious, having difficulty in falling asleep and often waking up with panic attacks, mainly linked to a fear of dying. In such a delicate transition phase as the one between the end

2 According to Italian legislation on privacy (Law 196/2003), students that refer to the Counselling Centre complete and sign an informed consent allowing data entry and storage. In order to ensure student confidentiality, the names have been changed. 
of university studies and entering employment there are anxieties linked to uncertainty about finding a suitably satisfying job. The first meeting made it clear to her that the counselling service did not offer concrete solutions for overcoming her symptoms, but instead offered the opportunity to reflect, together with the counsellor, and to give expression and meaning to one's past experiences so that the person would be more aware of his or her emotions and thus less frightened.

Giulia was specializing in the food and wine industry and it seems not by chance that her symptom was linked to food, although her first degree had been in foreign languages. On learning of a new degree course specifically on food and wine she became very regretful: «Right now that I've finished: I could have got a better grounding». It is from these statements that Giulia seemed to show a very high ego-ideal: her need for perfection and fear of failure had generated a block represented by her symptom, on the one hand, and not having started drafting her final thesis, on the other.

Her second counselling session revealed that she found it easier to "talk about what I do than about me». Her symptom slowly disappeared to then appear again before every session: she always seemed worried about not knowing what to say during the session and her symptom gave her the opportunity to talk about herself.

Only in the fourth session did the symptom completely disappear. On that occasion she also reported wanting to get married and to have a family, but she also reported a sense of abandonment and fear of breaking away from her parents. In the sessions it was possible to reflect on this ambiguity with respect to her need for, and fear, of independence.

Giulia seemed to be grappling with the process of separation-identification from her family, but not only this. Her university graduation itself represented another kind of separation: from the university environment towards the taking on of a new identity. Separation also meant detaching and differentiating herself from internalized parental images in order to better define her own identity: to identify yourself, you need to understand your own feelings and interests.

To comply with the idea that others had of her, she had always tried to maintain her good-girl image - as someone committed who could manage to do everything well: "A role I feel I have to play more for other people's sake than for myself»; she thus neglected her own emotions and motivations, and conformed adhesively to reality.

From her third session on, her symptom seemed to relax: Giulia reported the restructuring of her room. She said, «It may perhaps seem a trifle», musing on the fact that she had changed her room from a childish style to what she called "an adult one», feeling more comfortable now in 
this new dimension. She also thought about changing her clothes by buying more formal ones which could be useful for future job interviews. She also started her bibliographic research for her thesis, and in the fourth counselling session reported having drafted the first chapter in just one week.

At the end of her counselling sessions, besides completely clearing up her somatic symptom, she showed enthusiasm in view of completing her university studies; she resumed some social contacts and paid more attention to her own emotional states.

In her fourth session she had a very relaxed air and smiled, wearing pleasant make-up, with very bright lipstick; asked how she felt, she replied for the first time: «Everything's great».

The feeling of being welcomed and contained seemed to have enabled her to reprocess her emotional difficulties and to mobilize her resources, getting into greater touch with her own emotions, recognizing the value of others and the possibility of placing trust in them. The affective world which had found a defensive expression in her body through somatization had now become more accessible in that it had become possible to reflect on it, to take it somewhat into metal consideration, and even to worry about it.

In her fourth session, she said: «I'm glad I came to this Service despite my initial doubts about a successful outcome»; she finally realized her misplaced fears and acknowledged the usefulness of the counselling treatment. Because the treatment was limited in time it did not give the opportunity to establish a relation of dependency and, in our view, it accelerated the reelaboration processes. If we add that the treatment was provided by the university itself, which the counsellor in some way represented, we see how the separation process was facilitated. The follow-up session came about at the same time as her final graduation.

During the counselling treatment, "the space to think» offered Giulia the chance not only and not so much to create a new image of the external reality, of the outside world, but also to start creating a new self-image and an image of her emotional life. It also gave her the chance to reflect on her future expectations and fantasies concerning the job she would like, thereby helping her to get over her academic block.

\title{
4. CONCLUSIONS AND DISCUSSION
}

From the two clinical vignettes presented we can see how some difficulty in emotional regulation interferes in the developmental tasks of young adults and has adverse effects on psychological wellbeing, with consequences on

\author{
ECPS Journal - 14/2016 \\ http://www.ledonline.it/ECPS-Journal/
}


academic performance. In particular, in the first case, Ivana's family experiences seemed to constitute a still active conflictual core interfering with the development of a competent and valid self-image; so much so that it had negative effects on the continuation of her university studies. The absence of any perception of an effective emotional mirroring on the part of her parents made it difficult for Ivana to establish contact with her outside world, which seemed full of negative unregulated emotions such as anxiety, shame and solitude. These were reflected in her sentimental relationships and peer relations. Her need for recognition as well as her low self-esteem may symbolically be reflected in her choice of degree course. Even the histrionic way Ivana related to others seems a protection of her fragile self-image and a strong relationship need. The counselling sessions helped her to give new meanings to her past experiences in order to facilitate the emotion regulating process and her identity-building.

In the case of Giulia, cognitive activity included intellectualization and rationalization mechanisms, thus situating at the cognitive level the elective strategy for controlling emotions and causing somatic symptoms such as her difficulty in swallowing.

In analyzing the counselling sessions we see that, for both Giulia and Ivana, the identity-building process is connected to the difficulty in re-elaborating expectations and relational dynamics present in their families of origin, highlighting how the independence construction process is crucial in identity-building. While, for Ivana, the difficulty in emotional regulation seemed to have had its greater outcome at the relational, academic and social level, in Giulia's case the difficulty in emotional regulation had a strong impact at the somatic level - which also had effects at the social level. Both students made their request for help at a crucial time in their university careers: the impasse was due to dissatisfaction in the choice of degree course, in Ivana's case, and the conclusion of university studies with uncertainty regarding the working world, in Giulia's case. Psychological counselling enabled both students to find more adaptive and satisfying functioning modalities: greater social openness, greater individual autonomy and a gradual remission of symptoms.

In conclusion, in the light of the elements reported in the introduction and of the reflections illustrated in the two clinical vignettes, we underline the importance of promoting university counselling services to help students find more functional strategies in their emotion regulation process: from the capacity to read one's emotional states and to give them meaning, to the development of the more adaptive behavioural responses to cope with the developmental tasks and the inevitably linked academic performance. 


\section{REFERENCES}

Adamo, S. M. G., Sarno, I., Preti, E., Fontana, M. R., \& Prunas, A. (2010). Brief psychodynamic counselling in a university setting. Procedia - Social and Behavioral Sciences, 5, 1151-1159.

Aldao, A., Nolen-Hoeksema, S., \& Schweizer, S. (2010). Emotion-regulation strategies across psychopathology: A meta-analytic review. Clinical Psychology Review, 30(2), 217-237.

Aldea, M. A., \& Rice, K. G. (2006). The role of emotional dysregulation in perfectionism and psychological distress. Journal of Counseling Psychology, 53(4), 498-510.

Berking, M., \& Wupperman, P. (2012). Emotion regulation and mental health: Recent findings, current challenges, and future directions. Current Opinion in Psychiatry, 25(2), 128-134.

Biasi, V., Bonaiuto, P. (2012). The scientific contribution of the clinical method in educational research: A case study [Il portato scientifico del metodo clinico nelle applicazioni educative: un studio di caso]. Journal of Educational, Cultural and Psychological Studies, 6, 107-127.

Biasi, V., Bonaiuto, P., \& Giannini, A. M. (2010). Measures of emotional and motivational processes activated by stress or comfort conditions. Key Engineering Materials, 437, 540-544.

Biasi, V., Bonaiuto, P., Patrizi, N., \& Levin, J. (2015). The effectiveness of clinical colloquium established by the «drawing recall» technique in University Counselling Services for Student mental health. Health, 7, 521-532.

Biasi, V., Mallia, L., Menozzi, F., \& Patrizi, N. (2015). Adaptive functioning and behavioral, emotional and social problems of Italian university students: Indications for the University Counseling Services. Procedia - Social and Behavioral Sciences, 205, 66-69. http://www.sciencedirect.com

Biasi, V., Patrizi, N., Mosca, M., \& De Vincenzo, C. (2016). The effectiveness of university counselling for improving academic outcomes and wellbeing. British Journal of Guidance \& Counselling, 1-10. Online publication date: 03/12/2016.

Cole, P. M., Martin, S. E., \& Dennis, T. A. (2004). Emotion regulation as a scientific construct: Methodological challenges and directions for child development research. Child Development, 75, 317-333.

Eisenberg, N., Fabes, R. A., Guthrie, I. K., \& Reiser, M. (2000). Dispositional emotionality and regulation: Their role in predicting quality of social functioning. Journal of Personality and Social Psychology, 78(1), 136-157.

Gratz, K. L., \& Roemer, L. (2004). Multidimensional assessment of emotion regulation and dysregulation: Development, factor structure, and initial validation of the difficulties in emotion regulation scale. Journal of Psychopathology and Behavioral Assessment, 26(1), 41-54. 
Hayes, A. M., \& Feldman, G. (2004). Clarifying the construct of mindfulness in the context of emotion regulation and the process of change in therapy. Clinical Psychology: Science and Practice, 11(3), 255-262.

Hohenshil, T. H., Amundson, N. E., \& Niles, S. G. (Eds.). (2013). Counseling around the world: An international handbook. Alexandria, VA: American Counseling Association.

Kassel, J. D., Bornovalova, M., \& Mehta, N. (2007). Generalized expectancies for negative mood regulation predict change in anxiety and depression among college students. Behaviour Research and Therapy, 45(5), 939-950.

Lopes, P. N., Salovey, P., Côté, S., Beers, M., \& Petty, R. E. (2005). Emotion regulation abilities and the quality of social interaction. Emotion, 5(1), 113-118.

McLaughlin, K. A., Hatzenbuehler, M. L., Mennin, D. S., \& Nolen-Hoeksema, S. (2011). Emotion dysregulation and adolescent psychopathology: A prospective study. Behaviour Research and Therapy, 49(9), 544-554.

Mennin, D. S., Heimberg, R. G., Turk, C. L., \& Fresco, D. M. (2005). Preliminary evidence for an emotion dysregulation model of generalized anxiety disorder. Behaviour Research and Therapy, 43(10), 1281-1310.

Monti, F., Tonetti, L., \& Ricci Bitti, P. E. (2014). Comparison of cognitivebehavioural therapy and psychodynamic therapy in the treatment of anxiety among university students: An effectiveness study. British Journal of Guidance \& Counselling, 42(3), 233-244.

Monti, F., Tonetti, L., \& Ricci Bitti, P. E. (2015). Short-term effectiveness of psychotherapy treatments delivered at a university counselling service. British Journal of Guidance \& Counselling, 1-9. Online publication date: 11/12/2015.

Morris, A. S., Silk, J. S., Steinberg, L., Myers, S. S., \& Robinson, L. R. (2007). The role of the family context in the development of emotion regulation. Social development, 16(2), 361-388.

Park, C. L., Edmondson, D., \& Lee, J. (2012). Development of self-regulation abilities as predictors of psychological adjustment across the first year of college. Journal of Adult Development, 19(1), 40-49.

Rajappa, K., Gallagher, M., \& Miranda, R. (2012). Emotion dysregulation and vulnerability to suicidal ideation and attempts. Cognitive Therapy and Research, 36(6), 833-839.

Rice, K. G., \& Van Arsdale, A. C. (2010). Perfectionism, perceived stress, drinking to cope, and alcohol-related problems among college students. Journal of Counseling Psychology, 57(4), 439.

Rizq, R. (2010). Psychodynamics approaches. In R. Woolfe, S. Strawbridge, B. Douglas, \& W. Dryden (Eds.), Handbook of counselling psychology (pp. 85-104). London: Sage.

Selby, E. A., Anestis, M. D., \& Joiner, T. E. (2008). Understanding the relationship between emotional and behavioral dysregulation: Emotional cascades. Behaviour Research and Therapy, 46(5), 593-611. 
Spear, L. P. (2000). The adolescent brain and age-related behavioral manifestations. Neuroscience \& Biobehavioral Reviews, 24(4), 417-463.

Spear, L. P. (2013). Adolescent neurodevelopment. Journal of Adolescent Health, 52(2), S7-S13.

Steinberg, L. (2005). Cognitive and affective development in adolescence. Trends in Cognitive Sciences, 9(2), 69-74.

Thompson, R. A. (1994). Emotion regulation: A theme in search of definition. Monographs of the Society for Research in Child Development, 59(2-3), 25-52.

Wilcox, H. C., Arria, A. M., Caldeira, K. M., Vincent, K. B., Pinchevsky, G. M., \& O'Grady, K. E. (2012). Longitudinal predictors of past-year non-suicidal self-injury and motives among college students. Psychological Medicine, 42(4), 717-726.

\section{Riassunto}

Il presente lavoro si propone di discutere l'intervento psicodinamico fornito in un Centro di consulenza per studenti universitari. Secondo la metodologia e la procedura adottate il trattamento è psicodinamicamente orientato e si articola in quattro sedute settimanali e una quinta sessione programmata a distanza di tre mesi ("follow-up"). La riflessione presentata è focalizzata su una problematica clinica molto frequentemente riportata dagli studenti universitari che utilizzano i servizi di consulenza: la disregolazione emozionale. Vengono illustrate due vignette cliniche e riferiti i principali effetti ottenuti grazie alla consulenza psicodinamica, sullo sviluppo adattativo e sul funzionamento psicologico caratterizzato da un incremento dei comportamenti volti alla socializzazione e all'autonomia, oltre ad una progressiva migliore definizione di identità. Infine, alla luce dei dati raccolti, si sottolinea l'importanza della promozione dei Servizi di Counselling Universitari per aiutare gli studenti a trovare strategie piu funzionali nel processo di regolazione delle emozioni: dalla capacità di leggere i propri stati emotivi e di attribuire loro un significato, allo sviluppo di risposte comportamentali piu adattive per fronteggiare $i$ compiti evolutivi e le inevitabilmente collegate performances accademiche.

Parole chiave: Consulling universitario, Disregolazione emotive, Funzionamento psicologico adattivo, Studente universitario, Vignette cliniche.

How to cite this Paper: Menozzi, F., Gizzi, N., Tucci, M. T., Patrizi, N., \& Mosca, M. (2016). Emotional dysregulation: The clinical intervention of Psychodynamic University Counselling [Disregolazione emotiva: l'intervento clinico fornito dal Counselling Psicodinamico Universitario]. Journal of Educational, Cultural and Psychological Studies, 14, 169-182. doi: 10.7358/ecps-2016-014-meno 